\title{
Assimilation and partitioning of prey nitrogen within two anthozoans and their endosymbiotic zooxanthellae
}

\author{
Gregory A. Piniak $^{1,4, *}$, Fredric Lipschultz ${ }^{2}$, James McClelland ${ }^{3}$ \\ ${ }^{1}$ Duke University Marine Laboratory, 135 Duke Marine Lab Road, Beaufort, North Carolina 28516, USA \\ ${ }^{2}$ Bermuda Biological Station for Research, 17 Biological Lane, Ferry Reach, St. George's GE01, Bermuda \\ ${ }^{3}$ The Ecosystems Center, Marine Biological Laboratory, 7 MBL Street, Woods Hole, Massachusetts 02543, USA \\ ${ }^{4}$ Present address: USGS Pacific Science Center, 1156 High Street, Santa Cruz, California 95064, USA
}

\begin{abstract}
The movement of nitrogen from zooplankton prey into the temperate scleractinian coral Oculina arbuscula and the anemone Aiptasia pallida was measured using ${ }^{15} \mathrm{~N}$-labeled brine shrimp. The efficiency with which prey nitrogen was incorporated into cnidarian tissues was species-specific. O. arbuscula with a full complement of zooxanthellae had an assimilation efficiency of nearly $100 \%$, compared to only $46 \%$ for corals containing few zooxanthellae. In A. pallida, symbiont density had no effect, and nitrogen assimilation was 23 to $29 \%$. In both species, the host retained the bulk of the ingested label. Complete digestion was rapid $(<4 \mathrm{~h})$, as was the partitioning of the label between host amino acids and macromolecules. The label was primarily in the low-molecular weight-amino acid pool in O. arbuscula, where it remained for $30 \mathrm{~h}$. A maximum of ca. $20 \%$ of the ${ }^{15} \mathrm{~N}$ appeared in the zooxanthellae, where it was rapidly converted into macromolecules. Individual amino acids in A. pallida tissues were highly labeled with ${ }^{15} \mathrm{~N}$ within $4 \mathrm{~h}$ and showed no subsequent enrichment with time; however, zooxanthellae amino acids became increasingly enriched over $30 \mathrm{~h}$. Differences in ${ }^{15} \mathrm{~N}$ enrichment among amino acids were consistent with known synthesis and transformation pathways, but it was not possible to discriminate between host feeding and de novo synthesis.
\end{abstract}

KEY WORDS: Nitrogen $\cdot{ }^{15} \mathrm{~N} \cdot$ Assimilation efficiency $\cdot$ Oculina arbuscula $\cdot$ Aiptasia pallida

\section{INTRODUCTION}

Corals can ingest a wide variety of particles, including zooplankton (Coles 1969, Johannes et al. 1970, Johannes \& Tepley 1974, Porter 1974), bacteria (Sorokin 1973, Bak et al. 1998), ciliates (Ferrier-Pages et al. 1998), and suspended particulate matter (Lewis 1977, Mills \& Sebens 1997, Anthony 1999, 2000, Anthony \& Fabricius 2000). Prey items are captured using nematocysts on the tentacles, cilia and mucus nets, or a combination of these mechanisms (Boschma 1925, Goreau et al. 1971, Lewis \& Price 1975). Digestion initially takes place in the coelenteron, followed by intracellular digestion mediated by host mesenterial filaments (Boschma 1925). In anemones, digestion takes from $1 \mathrm{~h}$ (Clayton 1986) to $24 \mathrm{~h}$ (Nicol 1959); in corals, crustaceans 'disappear' within $3 \mathrm{~h}$ (Porter 1974).

In the field, prey are often in low abundance or patchily distributed (Johannes et al. 1970) and, instead of relying on heterotrophic inputs, corals in shallow tropical waters derive most of their energy from photosynthetic products of symbiotic zooxanthellae (e.g. Muscatine 1990). For example, Edmunds \& Davies $(1986,1989)$ so rarely observed zooplankton within Porites porites polyps that heterotrophic input for an energy budget was assumed to be zero. Nevertheless, prey capture may provide a rare but rich source of nutrients needed for growth, such as nitrogen, phosphorus, or essential amino acids (Johannes et al. 1970). However, measurements of the assimilation of prey 
nitrogen by cnidarians are lacking, and nutrient budgets often remain unbalanced (Roberts et al. 1999a) or assume that zooplanktivory balances any demand that inorganic uptake cannot meet (Bythell 1988, Rahav et al. 1989). Bythell (1988) calculated that particulate feeding is required to satisfy $70 \%$ of the nitrogen demand in the Acropora palmata symbiosis, and Rahav et al. (1989) estimated that $90 \%$ of the nitrogen used by zooxanthellae in Stylophora pistillata is recycled from the host (i.e. not new inputs). Few nutrient budgets have actually measured heterotrophic inputs, and none have directly measured the incorporation of prey nitrogen into cnidarian tissue. For example, Anthony (1999) estimated stoichiometrically from carbon assimilation that suspended particulate matter could provide up to $33 \%$ of the nitrogen required for growth in Pocillopora damicornis.

An additional serious shortcoming of nutrient budgets is that no quantitative data exist for the flux of nitrogen between the animal host and symbiotic algae; this problem is a major criticism of the nitrogen recycling hypothesis (Wang \& Douglas 1998). While researchers have for years assumed that zooxanthellae obtain waste products from host feeding (Boschma 1925, Yonge \& Nicholls 1931), the use of host nitrogen by zooxanthellae is largely inferred from excretion studies (e.g. Szmant-Froelich \& Pilson 1977, Muscatine $\&$ D'Elia 1978). The only direct evidence for transfer of prey nitrogen to zooxanthellae is unpublished data cited by Wilkerson \& Kremer (1992) for the scyphozoan Linuche unguiculata. However, several radio-labeled prey experiments indicate that zooxanthellae obtain sulphur, phosphorus, and carbon from host feeding (Cook 1971, 1972, Szmant-Froelich 1981, Thorington \& Margulis 1981, Steen 1986).

Internal amino acid pools have been used as an index of nutrient limitation in cnidarians (e.g. Ferrier 1992, McAuley 1994), but recently amino acid synthesis has drawn considerable interest. The traditional view is that animals satisfy essential amino acid requirements through the diet; however, in the case of cnidarians, symbiotic algae may be an alternative source. Based on ${ }^{14} \mathrm{C}$ evidence, the host can receive small amounts of amino acids from the zooxanthellae (Muscatine \& Cernichiari 1969, Lewis \& Smith 1971, Sutton \& Hoegh-Guldberg 1990, Markell \& Trench 1993), including several essential amino acids (Wang \& Douglas 1999). Recent ${ }^{14} \mathrm{C}$ tracer studies have demonstrated the synthesis of essential amino acids in anemones (Swanson \& Hoegh-Guldberg 1998, Roberts et al. 1999b, Wang \& Douglas 1999) and corals (FitzGerald \& Szmant 1997). Host synthesis of essential amino acids implies that cnidarians may have a reduced essential amino acid requirement compared to other metazoans (FitzGerald \& Szmant 1997).
This research used isotope ratio mass spectrometry (IRMS) and a stable isotope tracer $\left({ }^{15} \mathrm{~N}\right)$ to measure the assimilation and partitioning of ingested prey nitrogen by symbiotic corals and anemones. These experiments tested the following hypotheses: (1) that zooxanthellae acquire nitrogen from prey ingested by the host; (2) that the assimilation efficiency of prey nitrogen is species-specific, and decreases in the absence of zooxanthellae; (3) that prey capture provides the host with essential amino acids.

\section{MATERIALS AND METHODS}

Assimilation efficiency in Oculina arbuscula. Small colonies of the facultatively symbiotic temperate coral Oculina arbuscula were collected from the wreck of the Liberty ship 'Parker', an artificial reef (AR315) at $34^{\circ} 41^{\prime} 10^{\prime \prime} \mathrm{N}$, $76^{\circ} 43^{\prime} 30^{\prime \prime} \mathrm{W}$, approximately 3.9 nautical miles from Beaufort Inlet, NC. Colonies collected from the top of the wreck at $10 \mathrm{~m}$ depth were dark brown and contained high densities of zooxanthellae (HD), while colonies obtained from the interior and the sides of the wreck at $17 \mathrm{~m}$ were white and contained few zooxanthellae (LD; ca. $1 \%$ of HD zooxanthellae). The colonies were returned to the Duke University Marine Laboratory and converted into nubbins (Davies 1995) by cutting individual branches from the colonies and mounting them in plastic tubing (Tygon R3603). For $3 \mathrm{wk}$ prior to the experiment, nubbins were kept in aerated, filtered (polypropylene filter bag, mesh size $5 \mu \mathrm{m}$ ) seawater (salinity 33 to $35 \mathrm{ppt}, 0.3 \mu \mathrm{M}$ ambient $\mathrm{NH}_{4}^{+}$) in an incubator at $25^{\circ} \mathrm{C}$. LD nubbins were maintained in black plastic chambers within the incubator, while HD branches were kept in clear plastic boxes covered with a diffuser. The incubator was kept on a 12:12 h light:dark cycle with light provided by two $40 \mathrm{~W}, 50: 50$ actinic blue:natural daylight bulbs $(41.5 \mu \mathrm{E}$ $\mathrm{m}^{-2} \mathrm{~s}^{-1}$ ). All corals were fed to repletion twice weekly with freshly hatched brine shrimp nauplii; the water in the chamber was changed the day after each feeding bout (i.e. twice weekly).

The night before the experiment, the coral nubbins were removed from their Tygon tubing and individually placed in clear film canisters within the plastic incubator boxes. At $4 \mathrm{~h}$ before the light portion of the cycle, each coral was fed a ration of live Artemia franciscana that had been reared for 1 mo on ${ }^{15} \mathrm{~N}$-enriched Dunaliella tertiolecta $\left(99 \%{ }^{15} \mathrm{~N}\right.$ f/2 media $)$. A ration was $74.6 \pm 14.6 \mu \mathrm{g}$ (mean $\pm \mathrm{SD}$ ), and had an atom percentage enrichment (APE) of $17.4 \pm 0.7$. Samples ( $\mathrm{n}=3$ nubbins) of each coral type were collected 4,16 , 28, and $52 \mathrm{~h}$ after feeding, so that sample collection coincided with a new phase of the incubator's light:dark cycle. The water in the film canisters was 
collected for $\mathrm{NH}_{4}{ }^{+}$analysis every $12 \mathrm{~h}$ after the initial feeding period (Parsons et al. 1984), and replaced with new filtered seawater.

Coral tissue was removed from the skeleton by sonication with a Fisher model 60 sonic dismembrator (short bursts at $22.5 \mathrm{kHz}$, total sonication time $<30 \mathrm{~s}$ ) in a known volume of GF/F filtered seawater. The skeleton was retained for surface area measurements using the wax weight method (Stimson \& Kinzie 1991). The tissue slurry was centrifuged at $4700 \times g$ for $5 \mathrm{~min}$ to separate the host and zooxanthellae. The zooxanthellae pellet was resuspended and washed 3 times with $\mathrm{GF} / \mathrm{F}$ seawater; the final wash was resuspended to $2 \mathrm{ml}$, and passed through a double layer of $20 \mu \mathrm{m}$ Nitex mesh to remove nematocysts and other animal contamination. Subsamples of the zooxanthellae suspension were taken for microscopic determination of cell density with a Fuchs-Rosenthal hemacytometer. Aliquots of the homogenate, host, and zooxanthellae were spotted onto precombusted $25 \mathrm{~mm}$ GF/A filters for isotopic analysis. The host and zooxanthellae tissue were further separated into biochemical components by sequential extractions in room-temperature ethanol for 45 min (1:1 ethanol:tissue) and 5\% trichloroacetic acid at $4^{\circ} \mathrm{C}$ for $24 \mathrm{~h}$ (modified from Lenhoff \& Roffman 1971). Following each extraction, samples were centrifuged for $5 \mathrm{~min}$ at $13600 \times \mathrm{g}$. Aliquots of the ethanolsoluble (amino acids, low-molecular-weight compounds), TCA-insoluble (proteins, nucleic acids), and TCA-soluble (short amino acid chains, oligonucleotides) components were spotted onto precombusted $25 \mathrm{~mm}$ GF/A filters for isotopic analysis.

Assimilation efficiency and amino acid pools in Aiptasia pallida. We collected 2 types of the anemone Aiptasia pallida (Verrill) from the rock jetty at Shackleford Banks, NC: HD pigmented individuals, and LD white anemones. Anemones were returned to the laboratory and kept in plastic chambers in an incubator as described above for Oculina arbuscula. Anemones were maintained on a 12:12 h light:dark cycle (41.5 $\mu \mathrm{E} \mathrm{m}^{-2} \mathrm{~s}^{-1}$ ), fed to repletion twice weekly with freshly hatched brine shrimp, and given new filtered ( $5 \mu \mathrm{m}$ mesh) seawater $\left(25^{\circ} \mathrm{C}, 33\right.$ to $35 \mathrm{ppt}, 0.3 \mu \mathrm{M} \mathrm{NH}_{4}{ }^{+}$) twice weekly. On the day of the experiment, anemones were squirted vigorously with a pipet to remove mucus tunics and surface bacteria (FitzGerald 1991). The wet weight of each individual anemone was measured, and each animal placed in a sterilized $50 \mathrm{ml}$ polypropylene centrifuge tube. The tubes were filled with $0.2 \mu \mathrm{m}$ filtered autoclaved seawater (ASW), and treated with antibiotics (10000 U Penicillin G/ml, $10 \mathrm{mg}$ streptomycin/ml, working concentration $10 \mathrm{ml}$ antibiotics $\mathrm{l}^{-1}$ ASW; modified from Wang \& Douglas 1999). After $2 \mathrm{~h}$ in the antibiotic dip, the water in the tubes was replaced with fresh ASW. Anemones were fed a ration
$(8.0+2.1 \mu \mathrm{g} \mathrm{N}, 13.9+0.5$ APE) of live brine shrimp that had been reared for $2 \mathrm{wk}$ on unlabeled Dunaliella tertiolecta and $1 \mathrm{wk}$ on ${ }^{15} \mathrm{~N}$-enriched algae (f/2 media, $25 \%{ }^{15} \mathrm{~N}$ ).

Following collection, each anemone was individually sonicated in ASW $(22.5 \mathrm{kHz}$ for $<5 \mathrm{~s})$. The homogenate was centrifuged at $4700 \times g$ for $10 \mathrm{~min}$ to separate the host and zooxanthellae. Zooxanthellae were washed and counted in the same way as the coral samples described above. Aliquots of homogenate, host, and zooxanthellae tissue ( $\mathrm{n}=5$ per treatment) were spotted onto precombusted $25 \mathrm{~mm}$ GF/A filters for isotopic analysis. For each time point, the remaining host or zooxanthellae samples were aggregated and dried at $60^{\circ} \mathrm{C}$ and then hydrolyzed, purified and derivatized, according to the methods of Metges et al. (1996), in preparation for ${ }^{15} \mathrm{~N}$ analysis of individual amino acids.

Isotopic measurements. ${ }^{15} \mathrm{~N}$ enrichment of the coral and anemone tissue samples was measured with a Europa 20/20 isotope ratio mass spectrometer, using urea and bovine serum albumin as standards. Mass spectrometry data were collected as atom percentage abundance ${ }^{15} \mathrm{~N}\left(\mathrm{APA}=\left[{ }^{15} \mathrm{~N} /{ }^{14} \mathrm{~N}+{ }^{15} \mathrm{~N}\right] \times 100\right)$ and converted to atom percentage excess $(\mathrm{APE}=\mathrm{APA}-0.366)$. Nitrogen masses and isotopic ratios were used to calculate the assimilation efficiency (AE) at each time point, defined as: $\mathrm{AE}=100 \times\left(\mu \mathrm{g}\right.$ homogenate ${ }^{15} \mathrm{~N}-0 \mathrm{~h}$ $\mu \mathrm{g}$ homogenate $\left.{ }^{15} \mathrm{~N}\right) / \mu \mathrm{g}$ Artemia ration ${ }^{15} \mathrm{~N}$. The $\mathrm{AE}$ were uncorrected for recycling of the tracer or excretory losses. The ${ }^{15} \mathrm{~N}$ content of derivatized amino acids from host and zooxanthellae samples was measured by gas chromatography/combustion/isotope ratio mass spectrometry (GC/C/IRMS) as described by McClelland \& Montoya (2002). Amino acid data were reported as $\delta^{15} \mathrm{~N}=1000 \times\left(\mathrm{R}_{\text {sample }}-\mathrm{R}_{\text {standard }}\right) / \mathrm{R}_{\text {standard, }}$ where $\mathrm{R}=$ $\left({ }^{15} \mathrm{~N} /{ }^{14} \mathrm{~N}\right)$.

Statistical analysis. This was conducted using Systat 9. Data were tested for homoscedasticity using Scheffe-Box tests, and normality assumptions were tested using the Kolmogorov-Smirnov test for goodness of fit (Sokal \& Rohlf 1995). Data were arcsin- or square root-transformed as necessary prior to ANOVA. For physical data not expected to change substantially over the course of the experiment (size, zooxanthellae counts), samples for all time points were pooled for statistical analysis. For bulk measurements (APE, AE, excretion), data were tested with 2-way ANOVAs (factors = symbiotic status, time); pre-feeding baseline data (where assimilation and enrichment were zero) were not included in the analysis. The biochemical nitrogen pools were analyzed with 1-way ANOVAs to compare pools within a single tissue type, to examine differences in a single pool over time, or to compare a single pool across tissue types. Tukey's test was used for post-hoc comparisons for all ANOVAs. 


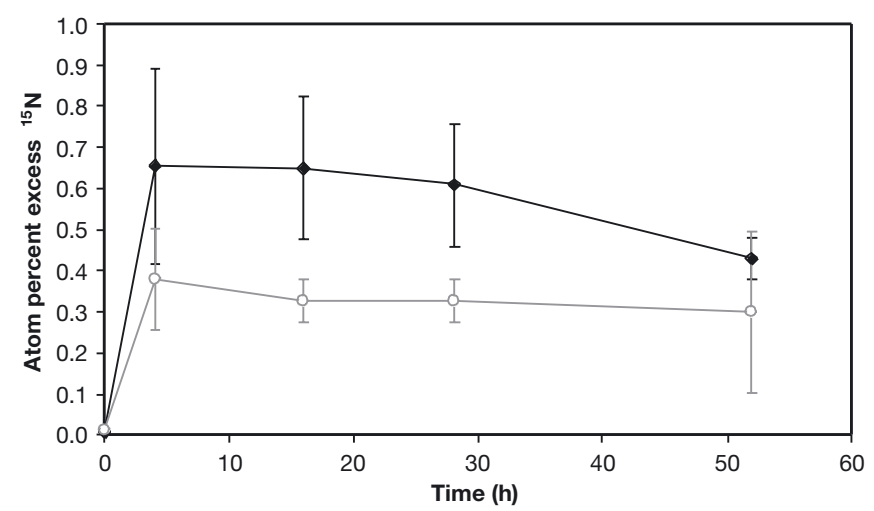

Fig. 1. Oculina arbuscula. Atom percentage excess ${ }^{15} \mathrm{~N}$ in coral tissue. Data are mean homogenate enrichment $(\mathrm{n}=3)$ for corals with high-density $(\bullet-)$ and low-density $(-\circ-)$ zooxanthellae. Error bars are standard deviations

\section{RESULTS}

\section{Oculina arbuscula}

The abundance of zooxanthellae had a significant effect on homogenate APE (Fig. 1, Table 1), with the ${ }^{15} \mathrm{~N}$ enrichment of HD Oculina arbuscula colonies being twice as high as that of LD specimens. Both HD and LD corals reached maximum enrichment within $4 \mathrm{~h}$, and APE was relatively constant for $2 \mathrm{~d}$ following feeding. HD corals had a mean AE of nearly $100 \%$, while LD animals had a mean AE of only $46 \%$ (Fig. 2, Table 1). These differences were reflected in the $\mathrm{NH}_{4}{ }^{+}$ excretion rates. Excretion was significantly higher in LD corals; rates were highest just after feeding and declined to a baseline within $16 \mathrm{~h}$ (Fig. 3, Table 1).

The partitioning of the label between the host and the algal symbiont differed in HD and LD Oculina arbuscula. LD specimens of $O$. arbuscula did contain zooxanthellae, but at $1.4 \times$ $10^{4}$ cells $\mathrm{cm}^{-2}$ zooxanthellae were 2 orders of magnitude less abundant than in HD corals $\left(1.2 \times 10^{6}\right.$ cells cm${ }^{-2}$; $\left.F_{1,28}=79.936, \mathrm{p}<0.001\right)$. HD hosts had a higher APE than LD hosts (Fig. 4A, Table 1), but there was no difference in the ${ }^{15} \mathrm{~N}$-enrichment of the zooxanthellae (Fig. 4B, Table 1). Based on mass, the majority of the label was found in the host; zooxanthellae contained $18 \%$ of the ${ }^{15} \mathrm{~N}$ in HD corals.

The biochemical distribution of ${ }^{15} \mathrm{~N}$ differed between the host, zooxanthellae in HD animals, and zooxanthellae in LD corals (Fig. 5). When host tissue was pooled over time, the amino acid pool contained the highest proportion of ${ }^{15} \mathrm{~N}$, while the TCA-soluble oligonucleotides formed the smallest pool (HD host $F_{2,42}=149.753, \mathrm{p}<0.001 ;$ LD host $F_{2,42}=172.039, \mathrm{p}<$ $0.001)$. The time course had no effect on the amino acid pool in LD hosts $\left(F_{4,10}=1.480, \mathrm{p}=0.279\right)$ but there was a significant effect of time on the HD host amino acid pool $\left(F_{4,10}=37.271, \mathrm{p}<0.001\right)$, which decreased in enrichment over time as the ${ }^{15} \mathrm{~N}$ was incorporated into insoluble protein. Regardless of time, host amino acid pools contained significantly more ${ }^{15} \mathrm{~N}$ than did zooxanthellae amino acids $\left(F_{3,56}=35.560, \mathrm{p}<0.001\right.$; LD host $=\mathrm{HD}$ host $>$ LD zooxanthellae $>$ HD zooxanthellae). Although HD zooxanthellae contained the most highly enriched oligonucleotides of any tissue type $\left(F_{3,56}=61.597, \mathrm{p}<\right.$ 0.001 ), more ${ }^{15} \mathrm{~N}$ was found in the protein pool than in any other HD zooxanthellae pool $\left(F_{2,42}=167.446, \mathrm{p}<\right.$ 0.001 ). The biochemical distribution of ${ }^{15} \mathrm{~N}$ in LD zooxanthellae was intermediate compared to host and HD zooxanthellae patterns; LD zooxanthellae contained equal proportions of ${ }^{15} \mathrm{~N}$ in the amino acid and protein pools, and both pools were significantly more enriched than the oligonucleotides $\left(F_{2,42}=155.328, \mathrm{p}<0.001\right)$.

\section{Aiptasia pallida}

HD Aiptasia pallida used in this experiment tended to be slightly, but not significantly, larger than LD anemones (Table 2). LD A. pallida tissue had higher APE ${ }^{15} \mathrm{~N}$ than HD anemones (Fig. 6A, Table 3), but the difference was significant only for the zooxanthellae (Fig. 6B, Table 3). HD animals had zooxanthellae densities 2 orders of magnitude greater than their LD counterparts (Table 2). There was no significant differ-

Table 1. Results of 2-way ANOVA results for Oculina arbuscula parameters. $\mathrm{APE}=$ atom percentage excess ${ }^{15} \mathrm{~N}$

\begin{tabular}{|lrrrr|}
\hline \multirow{2}{*}{ Parameter } & \multicolumn{1}{c}{ Factor } & df & \multicolumn{1}{c|}{$F$} & $\mathrm{p}$ \\
\hline Homogenate APE & Symbiotic status & 1,16 & 17.930 & 0.001 \\
& Time & 3,16 & 1.258 & 0.322 \\
& Interaction & 3,16 & 0.504 & 0.685 \\
Assimilation efficiency & Symbiotic status & 1,16 & 66.119 & $<0.001$ \\
& Time & 3,16 & 3.119 & 0.055 \\
& Interaction & 3,16 & 1.259 & 0.322 \\
$\mathrm{NH}_{4}{ }^{+}$excretion & Symbiotic status & 1,20 & 1204.115 & $<0.001$ \\
& Time & 4,20 & 397.563 & $<0.001$ \\
$\mathrm{Host}^{*}$ APE & Interaction & 4,20 & 12.497 & $<0.001$ \\
& Symbiotic status & 1,16 & 6.992 & 0.018 \\
\multirow{2}{*}{ Zooxanthellae APE } & Time & 3,16 & 0.262 & 0.852 \\
& Interaction & 3,16 & 0.433 & 0.732 \\
& Symbiotic status & 1,16 & 0.575 & 0.459 \\
& Time & 3,16 & 1.089 & 0.382 \\
& Interaction & 3,16 & 0.230 & 0.874 \\
\hline
\end{tabular}




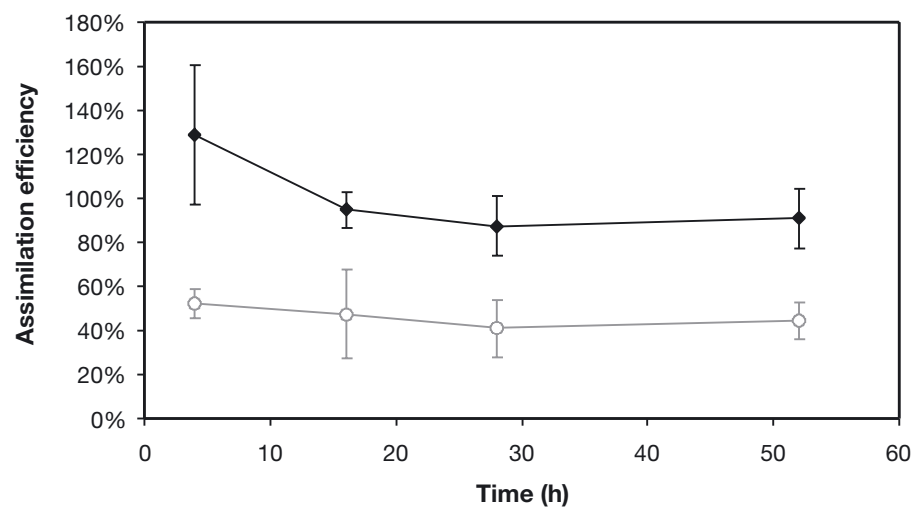

Fig. 2. Oculina arbuscula. Assimilation efficiency of prey ${ }^{15} \mathrm{~N}$ for corals with high-density $(\bullet-)$ and low-density $(-\circ)$ zooxanthellae $(\mathrm{n}=3)$. Error bars are standard deviations

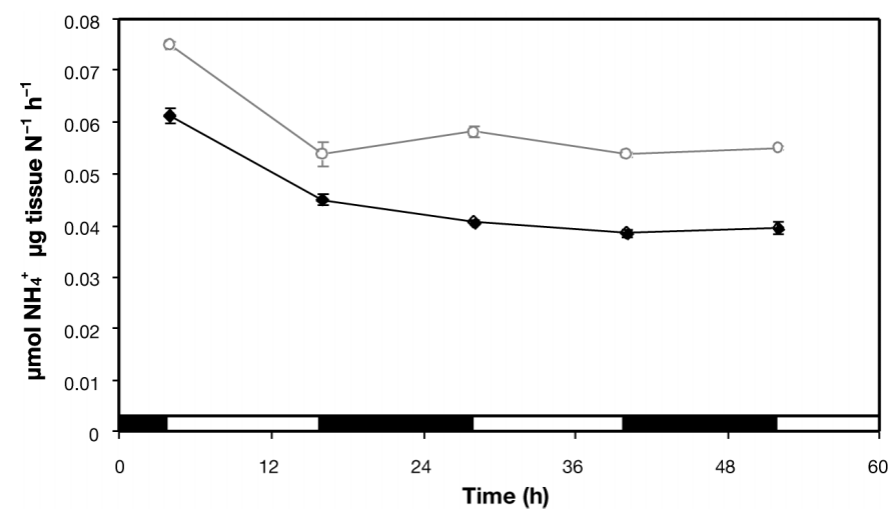

Fig. 3. Oculina arbuscula. Post-feeding $\mathrm{NH}_{4}{ }^{+}$excretion rates for corals with high-density $(\bullet-)$ and low-density $(-\circ)$ zooxanthellae. Error bars are standard deviations. Light and dark bars at the bottom of the graph indicate the stage of the photoperiod during the experiment

ence in AE between the 2 types of anemones (Table 2); zooxanthellae accounted for $21 \%$ of the ${ }^{15} \mathrm{~N}$ incorporated into $\mathrm{HD}$ anemones.

Amino acids in LD and HD hosts had similar isotopic signatures prior to feeding, although the essential amino acids were slightly higher in $\delta^{15} \mathrm{~N}$ in $\mathrm{HD}$ anemones (Fig. 7A), which ranged from -2 to $24 \%$. Both histidine and hydroxyproline were undetectable in the pre-fed host samples, while zooxanthellae contained all amino acids measurable by the analytical technique used (Fig. $7 \mathrm{~A}$ ). $\delta^{15} \mathrm{~N}$ values ranged from -4 to $7 \%$, and were generally lower than those of host amino acids. Following ingestion of the ${ }^{15} \mathrm{~N}$ tracer, the amino acid pools became highly labeled. In host tissue, the enrichment reached a plateau within $4 \mathrm{~h}$ (Fig. 7B,C) and remained relatively constant thereafter. HD anemones contained enriched histidine,
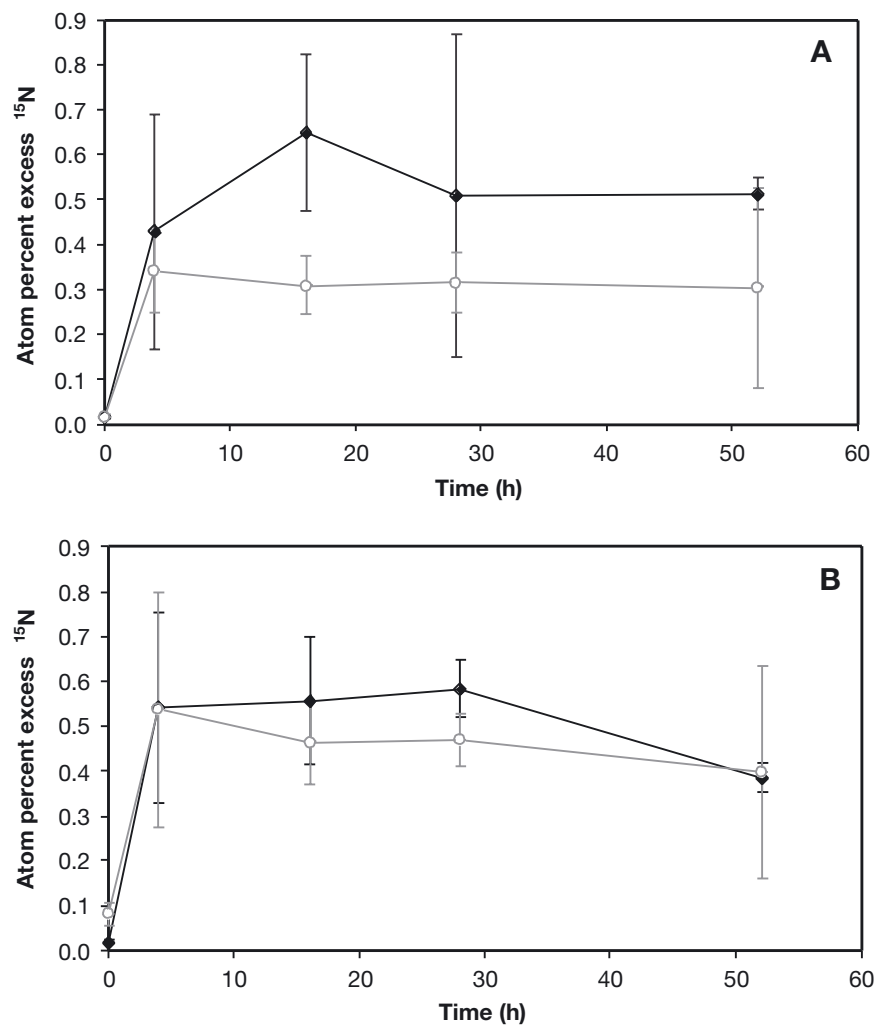

Fig. 4. Oculina arbuscula. Atom percentage excess ${ }^{15} \mathrm{~N}$ in highdensity ( $\bullet$ ) and low-density $(-\circ)$ tissue $(n=3)$ of $(A)$ host and

(B) zooxanthellae. Error bars are standard deviations

which was undetectable in LD hosts. The amino acids of LD hosts also tended to be slightly more enriched than their HD counterparts. Although the overall isotopic signatures were lower than in the host, the enrichment of all zoo-xanthellae amino acids continued to increase over the duration of the experiment (Fig. 7D). The zooxanthellae actively produced hydroxyproline, which did not appear in either HD or LD host tissue. Histidine was highly enriched within $4 \mathrm{~h}$, but was not measurable by $30 \mathrm{~h}$.

\section{DISCUSSION}

The ability of anemones and corals to take up dissolved inorganic nitrogen has been described many times (e.g. D'Elia \& Webb 1977, Muscatine \& D'Elia 1978, Burris 1983). However, other aspects of cnidarian nitrogen use are less well known: (1) dissolved organic nitrogen uptake has been rarely studied, (2) heterotrophic inputs and their relative importance can be difficult to quantify, (3) data on nitrogen assimilation efficiencies are lacking, and (4) fluxes of nitrogen between the cnidarian host and symbiotic zooxanthellae 


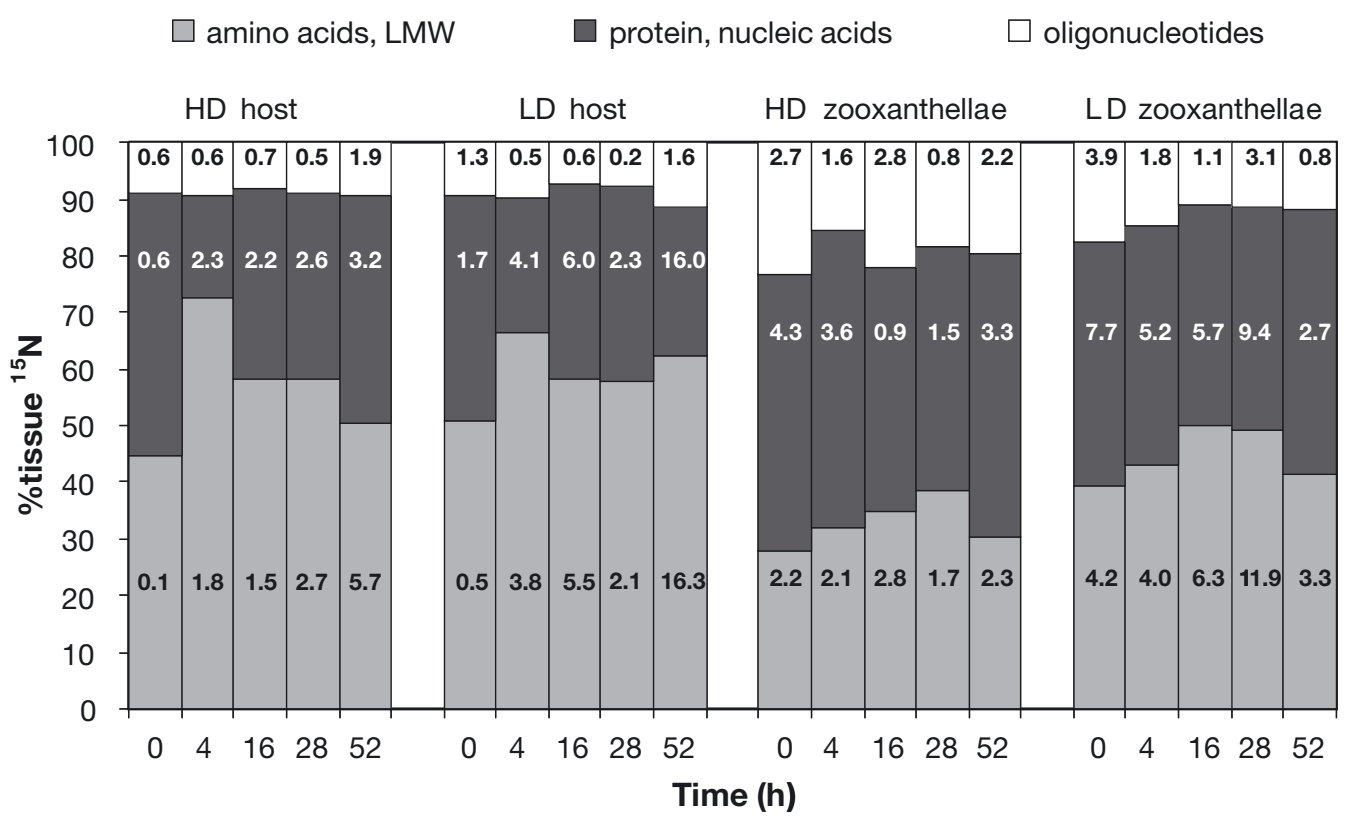

Fig. 5. Oculina arbuscula. Biochemical distribution of ${ }^{15} \mathrm{~N}$ within host and zooxanthellae tissue of coral with high-density (HD) and low-density (LD) zooxanthellae. Data $(n=3)$ are the mean percentage ${ }^{15} \mathrm{~N}$ in a biochemical pool, relative to the total amount of ${ }^{15} \mathrm{~N}$ in that tissue. Numbers on the graph bars indicate the standard deviation for that biochemical pool. LMW = low molecular weight

Table 2. Biomass and assimilation efficiency (AE) for anemone with high-density (HD) and low-density (LD) zooxanthellae. Assimilation data are averaged over time since there were no significant time $\left(F_{1,16}=0.597, \mathrm{p}=0.451\right)$ or interaction $\left(F_{1,16}=0.337\right.$, $\mathrm{p}=0.570$ ) effects (means $\pm \mathrm{SD})$

\begin{tabular}{|c|c|c|c|c|c|c|}
\hline \multirow[t]{2}{*}{ Parameter } & \multirow[t]{2}{*}{$\mathrm{n}$} & \multicolumn{2}{|c|}{ Anemones } & \multicolumn{3}{|c|}{ ANOVA } \\
\hline & & $\mathrm{HD}$ & LD & df & F & $\mathrm{p}$ \\
\hline Wet mass (g) & 15 & $0.73 \pm 0.23$ & $0.59 \pm 0.18$ & 1,28 & 3.523 & 0.071 \\
\hline Zooxanthellae [no. $(\mathrm{mg} \text { tissue } \mathrm{N})^{-1}$ ] & 15 & $8.12 \pm 3.40 \times 10^{7}$ & $3.46 \pm 1.88 \times 10^{5}$ & 1,28 & 104.434 & $<0.001$ \\
\hline AE (\%) & 10 & $23.0 \pm 9.4$ & $28.9 \pm 13.7$ & 1,16 & 1.194 & 0.291 \\
\hline
\end{tabular}

have not been adequately described. This lack of information requires either that cnidarian nitrogen budgets are left open and unbalanced (Roberts et al. 1999a), or the assumption that heterotrophy fulfills any demand that inorganic uptake cannot meet (Bythell 1988, Rahav et al. 1989). The present study describes the assimilation of prey nitrogen by cnidarians and the partitioning of that nitrogen between the host and its symbiotic zooxanthellae.

\section{Assimilation of prey nitrogen and the effects of zooxanthellae}

Because prolonged darkness or a lack of symbionts leads to increased rates of ammonium excretion (Szmant-Froelich \& Pilson 1977, Muscatine \& D'Elia 1978, Muscatine et al. 1979), symbiotic cnidarians should have higher AEs than those that lack zooxanthellae. In the present study, HD Oculina arbuscula assimilated more ${ }^{15} \mathrm{~N}$ (Fig. 2) and excreted less ammonium (Fig. 3) than LD colonies; this increased nitrogen retention would confer a growth advantage on HD corals. This is consistent with a positive correlation between chlorophyll a concentrations and $O$. arbuscula growth rate, although the effects of light and heterotrophy are approximately additive for this species (Miller 1995). Any growth of algal populations could also increase nitrogen demand and therefore assimilation efficiency; however, we did not measure mitotic rates of the zooxanthellae, and the effect is likely small compared to the difference in the overall size of the algal populations.

The AEs in Oculina arbuscula (HD 100\%, LD 46\%) are similar to nitrogen retention calculated from ammonium excretion rates in the coral Astrangia 
Table 3. Results of 2-way ANOVA results for Aiptasia pallida parameters. $\mathrm{APE}=$ atom percentage excess ${ }^{15} \mathrm{~N}$

\begin{tabular}{|llccc|}
\hline Parameter & \multicolumn{1}{c}{ Factor } & df & $F$ & $\mathrm{p}$ \\
\hline Host APE & Symbiotic status & 1,16 & 1.334 & 0.265 \\
& Time & 1,16 & 0.022 & 0.883 \\
& Interaction & 1,16 & 0.817 & 0.380 \\
Zooxanthellae APE & Symbiotic status & 1,16 & 9.247 & 0.008 \\
& Time & 1,16 & 0.696 & 0.416 \\
& Interaction & 1,16 & 0.619 & 0.443 \\
\hline
\end{tabular}

danae (symbiotic 60 to $92 \%$, nonsymbiotic 42 to $76 \%$; Szmant-Froelich \& Pilson 1977). However, Szmant-Froelich \& Pilson (1984) found no effect of symbiotic status on the nitrogen $\mathrm{AE}$ of $A$. danae, as symbiotic colonies excreted less ammonium but more organic nitrogen than nonsymbiotic corals, resulting in similar AEs. These patterns may be less pronounced for other elements; symbiotic $A$. danae assimilated $66 \%$ of ingested brine shrimp ${ }^{14} \mathrm{C}$, only $10 \%$ more than nonsymbiotic colonies (SzmantFroelich 1981).
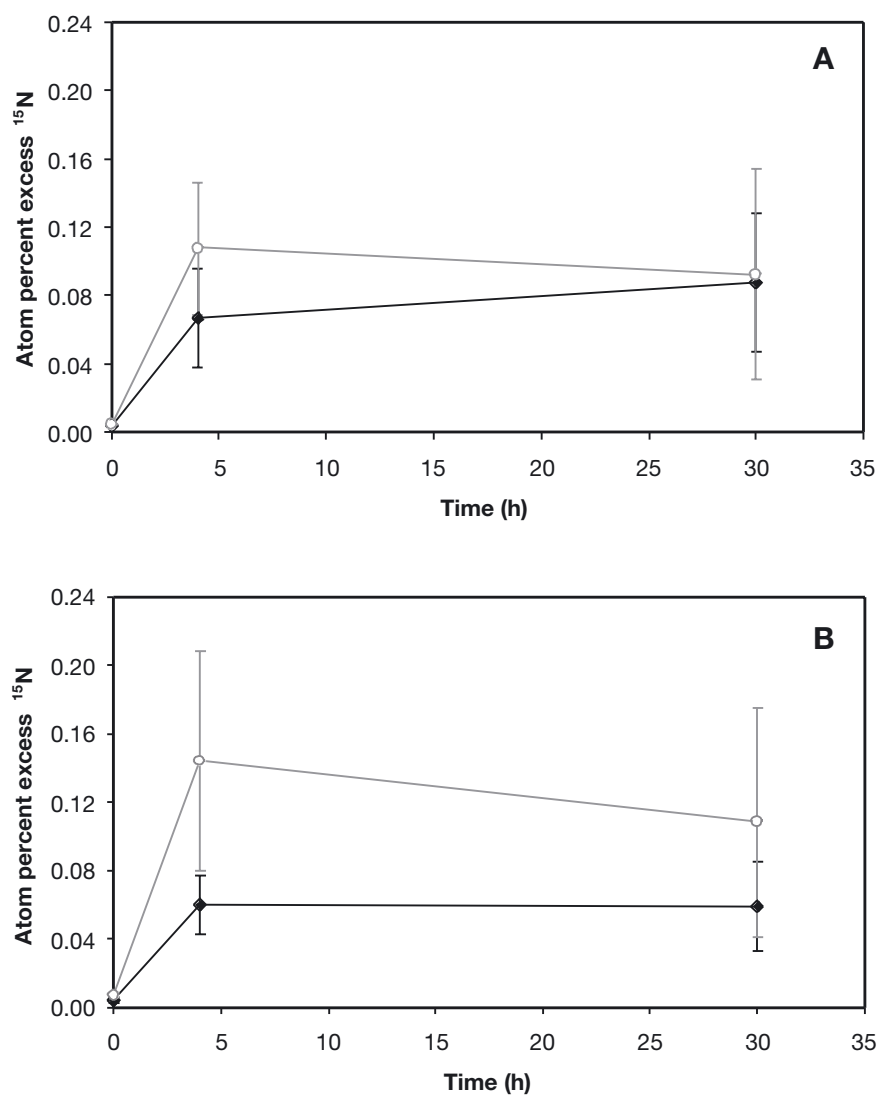

Fig. 6. Aiptasia pallida. Atom percentage excess ${ }^{15} \mathrm{~N}$ in highdensity $(--)$ and low-density $(-0)$ tissue $(n=5)$ of $(A)$ host and (B) zooxanthellae. Error bars are standard deviations
Anemones are often used as model coral polyps, and zooxanthellae are thought to function in the same way in the anthozoan hosts studied here. However, neither assumption may hold for the assimilation of prey nitrogen. In the anemone Aiptasia pallida, nitrogen assimilation was very low (23 to $29 \%$ ) compared to that in (1) the coral Oculina arbuscula (present study), (2) other anemones (75 to $94 \%$ for symbiotic Anthopleura elegantissima, Zamer 1986). Symbiotic state affected nitrogen assimilation in $O$. arbuscula but not in A. pallida, even though the range of ration sizes (1 to $10 \%$ of body mass) and relative abundance of zooxanthellae (LD specimens $1 \%$ that of HD specimens) were the same for both species. LD A. pallida had higher nitrogen assimilation than HD anemones but the difference was not significant. Other studies have also found that zooxanthellae do not necessarily enhance $\mathrm{AE}$ in anemones; for example, aposymbiotic Aiptasia pulchella incubated in darkness had an AE of $42 \%$ for ${ }^{35} \mathrm{~S}$, i.e. twice as high as symbiotic anemones (20 to $25 \%$ ) (Steen 1986).

Care should be taken when applying an AE to an energy or nutrient budget. Assimilation may depend on symbiotic state (Szmant-Froelich \& Pilson 1977, Steen 1986, present study), the amount of material ingested (Anthony 1999, but see Clayton 1986), feeding history (Szmant-Froelich \& Pilson 1984) or other factors such as temperature. Corals ingest a wide variety of zooplankton (Sebens et al. 1996, 1998), but it is unlikely that all prey are assimilated with equal efficiency. Despite this fact, most studies that measure assimilation rates simply use brine shrimp (SzmantFroelich 1981, Hunter 1984, Clayton 1986, Steen 1986, Zamer 1986, Lesser et al. 1994, present study), which are not natural prey items for cnidarians and may not adequately represent the assimilation of prey items in the field because of differences in nutritional content or body wall composition, for example. In addition, AEs measured in static laboratory conditions (such as the film canisters used in the present study) may overestimate assimilation, as cnidarians could uptake previously excreted material that would otherwise be advected away under field conditions.

\section{Partitioning of prey nitrogen}

In our study, zooxanthellae rapidly acquired ${ }^{15} \mathrm{~N}$ from live brine shrimp prey ingested by their anthozoan hosts (Aiptasia pallida, Oculina arbuscula). The rations used were small in relation to host biomass 

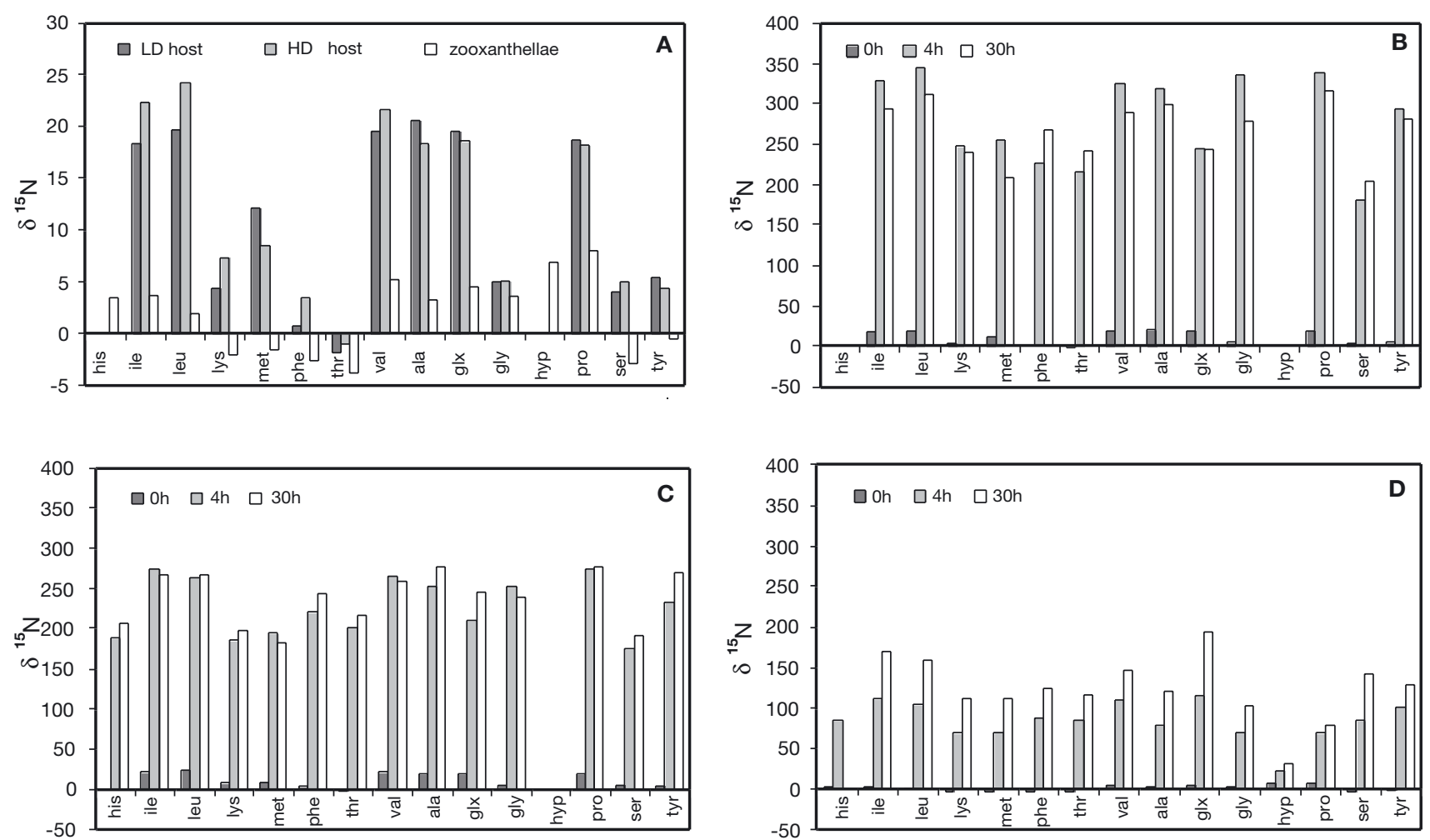

Fig. 7. Aiptasia pallida. $\delta^{15} \mathrm{~N}$ enrichment of amino acids in (A) pre-feeding (0 h) enrichments (host and algal symbiont); (B) lowdensity host tissue; (C) high-density host tissue; (D) zooxanthellae. Essential amino acids are listed on the left side of the graphs ( his $=$ histidine, ile $=$ isoleucine, leu $=$ leucine, lys $=$ lysine, met $=$ methionine, phe $=$ phenylalanine, thr $=$ threonine, val $=$ valine), while non-essential amino acids appear on the right (ala = alanine, glx = glutamine/glutamate, gly = glycine, hyp = hydroxyproline, pro $=$ proline, ser $=$ serine, tyr $=$ tyrosine). The data shown represent single injections of aggregated tissue samples. Analytical error for the natural abundance $\delta^{15} \mathrm{~N}$ samples is $\pm 1 \%$. Duplicate injections for the $4 \mathrm{~h}$ LD host indicate the standard deviations for the enriched tracer $\delta^{15} \mathrm{~N}$ values depend on the individual amino acid, and range from 0 to $23 \%$ (data not shown). Empty spaces in the graph represent peaks that were below detection limits

(typically 1 to $10 \%$ ), which should facilitate digestion and assimilation; although complete digestion is unlikely, egesta or fecal pellets were rarely observed. Therefore, our functional definition of assimilation is the breakdown of the basic structure of Artemia so that expulsion of egesta has no effect on the isotopic composition of the host. The tissue processing techniques cannot distinguish between cnidarian tissue and prey material not egested, so partially digested prey entangled in mesenterial filaments or prey items being digested in vacuoles would be considered assimilated based on our approach. By this definition, prey use occurs very rapidly, as both host and zooxanthellae reached maximum enrichment within 4 h (Figs. 4 \& 6). This appears to be a general response, as the same patterns have been observed in temperate anemones, temperate corals, and tropical corals (Piniak 2001), and the $4 \mathrm{~h}$ time frame is consistent with visual assessments of the coelenteron in anemones and corals (Nicol 1959, Porter 1974, Clayton 1986). Preliminary experiments indicated zooxanthellae can acquire nitrogen even more rapidly, as zooxanthellae obtain as much as half of the final amount of ${ }^{15} \mathrm{~N}$ within $30 \mathrm{~min}$ of ingestion (G. A. Piniak \& F. Lipschultz unpubl. data).

The mechanism by which the zooxanthellae obtained ${ }^{15} \mathrm{~N}$ from the prey is unclear. Captured prey items are processed in the coelenteron, where extracellular digestion takes place. Digestion is mediated by the mesenterial filaments; food particles become incorporated into the filaments within $1 \mathrm{~h}$ after feeding and can persist in the filaments for several days (Boschma 1925). The traditional recycling view is that ingested nitrogen is phagocytosed and broken down by the host; the digested products are then incorporated into host tissue and/or immediately catabolized, with waste nitrogen excreted or recycled by the zooxanthellae. Complete passage through host anabolic and catabolic pathways is inconsistent with the rapid appearance of label in the zooxanthellae found in this study; however, immediate host catabolism of prey nitrogen and subsequent uptake by zooxanthellae could account for the results. An alternative pathway is the direct use of 
digested material, e.g. ammonium or small molecules such as amino acids, via uptake from the coelenteron. Zooxanthellae can readily take up amino acids (Bester 1997), so complete reduction of prey items to dissolved inorganic nitrogen is not a necessary precondition for nitrogen uptake by the symbiotic algae. Any nitrogen digested within the coelenteron itself could therefore form a common pool resource for which both the host and zooxanthellae compete. This mechanism would also permit access to prey nitrogen by zooxanthellae, the bulk of which are located in the tentacles, far from the mesenteries where digestion occurs. Another possibility is utilization of nitrogen from the small volumes of incubation water in which the feeding experiments were carried out. Excretion from the animals resulted in constant rates of ammonium release into the water, even during darkness (Fig. 3), but the mass of nitrogen released in this way was far too small to account for the results. Zooxanthellae could also have taken up ${ }^{15} \mathrm{~N}$ excreted from the brine shrimp during the feeding period. However, the amount of label potentially gained by this means is likely small compared to the amount ingested by the coral or anemone.

Zooxanthellae acquired 10 to $20 \%$ of the ingested prey ${ }^{15} \mathrm{~N}$ mass. Incomplete homogenization of host tissue by sonication is a potential experimental artifact that could have biased this calculation. However, the proportion of ${ }^{15} \mathrm{~N}$ in zooxanthellae was the same for both anthozoan hosts despite the longer sonication required to remove tissue from the coral skeleton in Oculina arbuscula, and visual analysis during zooxanthellae counts indicated that the pellets for both species were relatively free of excess animal debris. In addition, the partitioning observed in this study compares well with previous labeled-prey studies that used other isotopic tracers and a wide variety of symbiotic partners, experimental conditions, and processing techniques. Zoochlorellae obtained 22 to $26 \%$ of prey ${ }^{14} \mathrm{C}$ ingested by hydra in the light, and 25 to $34 \%$ in darkness (Cook 1972). In the coral Astrangia danae, 10 to $20 \%$ of the ingested ${ }^{14} \mathrm{C}$ was found in zooxanthellae (Szmant-Froelich 1981). In Aiptasia pulchella fed ${ }^{35} \mathrm{~S}$-labeled brine shrimp, zooxanthellae retained 10 to $12 \%$ of the label after $3 \mathrm{~d}$ (Steen 1986) and 15 to $20 \%$ for 5 d (Cook 1971).

The distribution of the ${ }^{15} \mathrm{~N}$ label among the biochemical pools of the temperate coral Oculina arbuscula indicates that the host and the zooxanthellae use ingested nitrogen differently (Fig. 5). The distribution of label within the HD zooxanthellae remained constant; even $4 \mathrm{~h}$ after feeding, the majority of the label was in the protein fraction. By rapidly utilizing newly available nitrogen, zooxanthellae would contain small internal pools of dissolved nitrogen. This would maintain a concentration gradient for $\mathrm{NH}_{4}{ }^{+}$or amino acid precursors and enhance the ability of the zooxanthellae to take advantage of an infrequent but rich nitrogen source, such as prey items ingested by the host. In contrast, ${ }^{15} \mathrm{~N}$ in both $\mathrm{HD}$ and LD host tissues was primarily in the free amino acid pool, where enrichment remained constant in LD hosts but decreased in HD hosts as the label moved to the protein pool. This difference could be linked to the proportion of symbionts present, as more zooxanthellae implies a greater amount of carbon translocated to the host. Carbon from algal photosynthesis plays a key role in host assimilation of inorganic nitrogen (Lipschultz \& Cook 2002) and phosphorus (Kelty 2001); similarly photosynthate may provide carbon skeletons for protein synthesis. Alternatively, the increase in HD protein pool ${ }^{15} \mathrm{~N}$ could reflect preferential catabolism of photosynthetic carbon for energy (Szmant et al. 1990), thus allowing HD hosts to build larger protein reserves than LD hosts with a lower carbon supply.

Do zooxanthellae translocate nitrogenous compounds to Oculina arbuscula host tissue? If so, the proportion of ${ }^{15} \mathrm{~N}$ in the ethanol-soluble pool should increase rather than decrease. Sampling over longer time intervals may be required to answer this question; in one study, sampling over $245 \mathrm{~h}$ was necessary to demonstrate nitrogen translocation in symbiotic clams (Hawkins \& Klumpp 1995). Additional studies examining the composition of amino acid pools or utilizing inorganic ${ }^{15} \mathrm{~N}$ over long time courses may shed further light on whether $O$. arbuscula hosts receive any nitrogenous benefit from their zooxanthellae.

\section{Heterotrophy and amino acids}

At the beginning of the experiment, amino acids in the host Aiptasia pallida contained considerably more ${ }^{15} \mathrm{~N}$ than those in zooxanthellae (Fig. 7A). Higher host tissue enrichment could reflect translocation from zooxanthellae, or a combination of protein catabolism and excretion of isotopically light ammonium (Muscatine \& Kaplan 1994). Translocation is doubtful, as amino acid transport should have no fractionation effect; amination and deamination reactions are a more likely mechanism. The large isotopic difference between host and zooxanthellae is greater than the increase in bulk $\delta^{15} \mathrm{~N}$ values of $3 \%$ typically seen between trophic levels (Minagawa \& Wada 1984); the differences for individual amino acids can be higher or lower (McClelland \& Montoya 2002). The difference between glutamine/glutamate and phenylalanine $\left(\Delta \delta^{15} \mathrm{~N}_{\text {glu-phe }}\right)$ can be used as an indicator of trophic position: $\Delta \delta^{15} \mathrm{~N}_{\text {glu-phe }}$ is ca. $4 \%$ for phytoplankton, ca. $11 \%$ o for herbivores, and ca. $18 \%$ o for primary carnivores (McClelland \& Montoya 2002). LD hosts had a 
$\Delta \delta^{15} \mathrm{~N}_{\text {glu-phe }}$ of $19 \%$, while the $15 \%$ of HD hosts could reflect enhanced host uptake of $\mathrm{NH}_{4}{ }^{+}$driven by photosynthetic carbon. Zooxanthellae obtain enough host nitrogen to appear mixotrophic, as their $\Delta \delta^{15} \mathrm{~N}_{\text {glu-phe }}$ of $7 \%$ falls between primary producers and herbivores.

After feeding, all host amino acids increased dramatically in $\delta^{15} \mathrm{~N}$, with little variability between essential and non-essential amino acids, regardless of symbiotic state (Fig. 7B,C). Tyrosine and glutamine/glutamate enrichment increased in HD host tissue, which is consistent with host synthesis (via glutamine synthetase; Wang \& Douglas 1998). However, enrichment in these amino acids did not increase in LD hosts from 4 to $30 \mathrm{~h}$. Translocation from the zooxanthellae (Muscatine \& Cernichiari 1969, Sutton \& Hoegh-Guldberg 1990) is not supported by the data, since glutamine/glutamate in the zooxanthellae (Fig. 7D) always had a lower isotopic signature and could therefore not be the source for the host pool. Roberts et al. (1999b) also attempted to document translocation of amino acids to the host by providing ${ }^{15} \mathrm{~N}$-ammonium to Anemonia viridis. The nitrogen label did appear in host tissues, but because of difficulties in sample derivatization they were unable to discern whether the ${ }^{15} \mathrm{~N}$ was translocated from the zooxanthellae or directly assimilated by the host.

The $\delta^{15} \mathrm{~N}$ values of every zooxanthellae amino acid increased over the duration of the experiment (Fig. 7D). This may reflect de novo synthesis by the zooxanthellae, or the transfer of amino acids from the host in exchange for photosynthetic carbon (i.e. 'host factor'; Gates et al. 1995). However, transfer from the host must be limited, since the bulk zooxanthellae enrichment (Fig. 6B) did not change over time. Glutamine/glutamate was the most highly enriched zooxanthellae amino acid, which is not surprising because ammonium uptake in zooxanthellae is primarily via the glutamine synthetase pathway (Summons \& Osmond 1981, Anderson \& Burris 1987). Glutamine was also among the most commonly synthesized amino acids in Aiptasia pulchella zooxanthellae (Swanson \& HoeghGuldberg 1998).

Analysis of individual amino acids was insufficient to identify transfer pathways between the host and zooxanthellae, and could not discriminate between bulk transfer and de novo synthesis. As noted by Roberts et al. (1999b), such discrimination requires measurements much sooner than the $4 \mathrm{~h}$ used in this study, but the presence of undigested prey would hinder such an assessment. Use of ${ }^{15} \mathrm{NH}_{4}{ }^{+}$would also be complicated, since considerable ammonium is assimilated by the host (Lipschultz \& Cook 2002). Experiments with ${ }^{15} \mathrm{NO}_{3}$ could permit tracing nitrogen that can only be assimilated by zooxanthellae and so enable quantification of amino acid transport from the algal symbionts.

\section{Conclusions}

The present study described the assimilation of prey nitrogen by symbiotic cnidarians, and the partitioning of that nitrogen between the host and its symbiotic zooxanthellae. The results have implications for nutrient budgets in general, and nitrogen budgets in particular. This study is the first to demonstrate direct incorporation of prey nitrogen into anthozoan host and algal tissues, though the mechanisms by which zooxanthellae obtain ingested prey nitrogen remain unclear. Approximately 10 to $\sim 20 \%$ of assimilated ${ }^{15} \mathrm{~N}$ was found in the zooxanthellae. Because this result is similar to the findings of other anthozoan/zooxanthellae labeled-prey studies using sulfur and carbon (Cook 1971, Szmant-Froelich 1981, Steen 1986), nutrient budgets could generally assume a similar figure for the flux of nutrients from the host to the algae. However, AEs in this and other studies vary so much with species and environmental conditions that they should be determined for each unique nutrient budget. Because this study emphasized the processing of ingested prey nitrogen, the biochemical distribution of ${ }^{15} \mathrm{~N}$ in Oculina arbuscula and amino acid enrichments in Aiptasia pallida described here are insufficient to demonstrate nitrogen fluxes from the algal symbiont to the animal host, and quantification of such nutrient transfer awaits further study.

Acknowledgements. This manuscript was improved by comments from W. Kirby-Smith, L. Crowder, R. Forward, and 3 anonymous reviewers. This work was supported by the PADI Foundation, the National Science Foundation Dissertation Improvement Grant (\#9972616), and the Munson Foundation. This is Contribution \#1630 of the Bermuda Biological Station for Research.

\section{LITERATURE CITED}

Anderson SL, Burris JE (1987) Role of glutamine synthetase in ammonia assimilation by symbiotic marine dinoflagellates (zooxanthellae). Mar Biol 94:451-458

Anthony KRN (1999) Coral suspension feeding on fine particulate matter. J Exp Mar Biol Ecol 232:85-106

Anthony KRN (2000) Enhanced particle-feeding capacity of corals on turbid reefs. Coral Reefs 19:59-67

Anthony KRN, Fabricius KE (2000) Shifting roles of heterotrophy and autotrophy in coral energetics under varying turbidity. J Exp Mar Biol Ecol 252:221-253

Bak RPM, Joenje M, de Jong I, Lambrechts DYM, Nieuwland G (1998) Bacterial suspension feeding by coral reef benthic organisms. Mar Ecol Prog Ser 175:285-288

Bester CL (1997) Uptake of amino acids in cultured and freshly isolated zooxanthellae (Symbiodinium bermudense): the effects of exposure to exogenous amino acids on the cellular physiology of symbiotic algae. MSc thesis, Bowling Green State University, Bowling Green, $\mathrm{OH}$

Boschma H (1925) On the feeding reactions and digestion in the coral polyp Astrangia danae, with notes on its symbiosis with zooxanthellae. Biol Bull 49:407-439 
Burris RH (1983) Uptake and assimilation of ${ }^{15} \mathrm{NH}_{4}{ }^{+}$by a variety of corals. Mar Biol 75:151-155

Bythell JC (1988) A total nitrogen and carbon budget for the elkhorn coral Acropora palmata (Lamarck). Proc 6 Int Coral Reef Symp 2:535-540

Clayton W (1986) Ingestion, digestion and assimilation efficiency of the sea anemone Aiptasia pallida fed zooplankton prey. Int Rev Ges Hydrobiol 71:709-717

Coles S (1969) Quantitative estimates of feeding and respiration for three scleractinian corals. Limnol Oceanogr 14: 949-953

Cook CB (1971) Transfer of ${ }^{35} \mathrm{~S}$-labeled material from food ingested by Aiptasia sp. to its endosymbiotic zooxanthellae. In: Lenhoff H, Muscatine L, Davis LV (eds) Experimental coelenterate biology. University of Hawaii Press, Honolulu, p 218-224

Cook CB (1972) Benefit to symbiotic zoochlorellae from feeding by green hydra. Biol Bull 142:236-242

Davies PS (1995) Coral nubbins and explants for reef assessment and laboratory ecotoxicology. Coral Reefs 14: $267-269$

D'Elia CF, Webb KL (1977) The dissolved nitrogen flux of reef corals. Proc 3rd Int Coral Reef Symp 1:325-330

Edmunds PJ, Davies PS (1986) An energy budget for Porites porites (Scleractinia). Mar Biol 92:339-348

Edmunds PJ, Davies PS (1989) An energy budget for Porites porites (Scleractinia), growing in a stressed environment. Coral Reefs 8:37-44

Ferrier MD (1992) Fluxes and metabolic pools of amino acids in algal-cnidarian symbioses. $\mathrm{PhD}$ thesis, University of Maryland, College Park, MD

Ferrier-Pages C, Allemand D, Gattuso JP, Jaubert J, Rassoulzadegan F (1998) Microheterotrophy in the zooxanthellate coral Stylophora pistillata: Effects of light and ciliate density. Limnol Oceanogr 43:1639-1648

FitzGerald LM (1991) Amino acid metabolism of scleractinian corals. PhD thesis, University of Miami, Miami, FL

FitzGerald LM, Szmant AM (1997) Biosynthesis of 'essential' amino acids by scleractinian corals. J Biochem 322:213-221

Gates RD, Hoegh-Guldberg O, McFall-Ngai MJ, Bil KY, Muscatine L (1995) Free amino acids exhibit anthozoan 'host factor' activity: They induce the release of photosynthate from symbiotic dinoflagellates in vitro. Proc Natl Acad Sci USA 92:7430-7434

Goreau T, Goreau N, Yonge C (1971) Reef corals: autotrophs or heterotrophs? Biol Bull 141:247-260

Hawkins AJS, Klumpp DW (1995) Nutrition of the giant clam Tridacna gigas (L.). II. Relative contributions of filterfeeding and the ammonium-nitrogen acquired and recycled by symbiotic alga towards total nitrogen requirements for tissue growth and metabolism. J Exp Mar Biol Ecol 190:263-290

Hunter T (1984) The energetics of asexual reproduction: Pedal laceration in the symbiotic sea anemone, Aiptasia pulchella. J Exp Mar Biol Ecol 83:127-148

Johannes RE, Tepley L (1974) Sources of nutritional energy for reef corals. Proc 2nd Int Coral Reef Symp:133-137

Johannes RE, Coles S, Kuenzel N (1970) The role of zooplankton in the nutrition of some scleractinian corals. Limnol Oceanogr 15:579-586

Kelty R (2001) Phosphorus uptake and allocation in Aiptasia pallida and Madracis mirabilis. PhD thesis, University of Maryland, College Park, MD

Lenhoff HM, Roffman B (1971) Two methods for fractionating small amounts of radioactive tissue. In: Lenhoff HM, Muscatine L, Davis LV (eds) Experimental coelenterate biology. University of Hawaii Press, Honolulu, p 265-271
Lesser M, Witman J, Sebens KP (1994) Effects of flow and seston availability on scope for growth of benthic suspension-feeding invertebrates from the Gulf of Maine. Biol Bull 187:319-335

Lewis DH, Smith DC (1971) The autotrophic nutrition of symbiotic marine coelenterates with special reference to hermatypic corals. I. Movement of photosynthetic products between symbionts. Proc R Soc Lond Ser B 178:111-129

Lewis J (1977) Suspension feeding in Atlantic reef corals and the importance of suspended particulate matter as a food source. Proc 3rd Int Coral Reef Symp 1:405-408

Lewis JB, Price WS (1975) Feeding mechanisms and feeding strategies of Atlantic reef corals. J Zool Lond 176:527-544

Lipschultz F, Cook CB (2002) Uptake and assimilation of ${ }^{15} \mathrm{~N}$-ammonium by the symbiotic sea anemones Bartholomea annulata and Aiptasia pallida: conservation versus recycling of nitrogen. Mar Biol 140:489-502

Markell DA, Trench RK (1993) Macromolecules exuded by symbiotic dinoflagellates in culture: Amino acid and sugar composition. J Phycol 29:64-68

McAuley PJ (1994) Amino acid content of zooxanthellae freshly isolated from Pocillopora damicornis. Pac Sci 48:247-253

McClelland JW, Montoya JP (2002) Trophic relationships and the nitrogen isotopic composition of amino acids in plankton. Ecology 83:2173-2180

Metges CC, Petzke K, Hennig U (1996) Gas chromatography/ combustion/isotope ratio mass spectrometric comparison of $\mathrm{N}$-acetyl- and $\mathrm{N}$-pivaloyl amino acid esters to measure ${ }^{15} \mathrm{~N}$ isotopic abundances in physiological samples: A pilot study on amino acid synthesis in the upper gastrointestinal tract of minipigs. J Mass Spectrom 31:367-376

Miller MM (1995) Growth of a temperate coral: effects of temperature, light, depth, and heterotrophy. Mar Ecol Prog Ser 122:217-225

Mills MM, Sebens KP (1997) Particle ingestion efficiency of the corals Siderastrea siderea and Agaricia agaricites: Effects of flow speed and sediment load. Proc 8th Int Coral Reef Symp Panama 2:1059-1064

Minagawa M, Wada E (1984) Stepwise enrichment of ${ }^{15} \mathrm{~N}$ along food chains: further evidence and the relationship between $\delta^{15} \mathrm{~N}$ and animal age. Geochim Cosmochim Acta 48:1135-1140

Muscatine L (1990) The role of symbiotic algae in carbon and energy flux in reef corals. In: Dubinsky Z (ed) Ecosystems of the world, Vol 25. Coral Reefs. Elsevier, Amsterdam, p 75-87

Muscatine L, Cernichiari E (1969) Assimilation of photosynthetic products of zooxanthellae by a reef coral. Biol Bull 137:506-523

Muscatine L, D'Elia CF (1978) The uptake, retention, and release of ammonium by reef corals. Limnol Oceanogr 23: $725-734$

Muscatine L, Kaplan IR (1994) Resource partitioning by reef corals as determined from stable isotope composition, II. $\delta^{15} \mathrm{~N}$ of zooxanthellae and animal tissue versus depth. Pac Sci 48:304-312

Muscatine L, Masuda H, Burnap R (1979) Ammonium uptake by symbiotic and aposymbiotic reef corals. Bull Mar Sci 29:572-575

Nicol JAC (1959) Digestion in sea anemones. J Mar Biol Assoc UK 38:469-476

Parsons RT, Maita Y, Lalli CR (1984) A manual of chemical and biological methods for seawater analysis. Pergamon Press, Elmsford

Piniak GA (2001) The effects of symbiotic condition and nutritional history on prey capture and use by anemones and corals. PhD thesis, Duke University, Durham, NC 
Porter JW (1974) Zooplankton feeding by the Caribbean reefbuilding coral Montastrea cavernosa. Proc 2nd Int Coral Reef Symp, Brisbane 1:111-125

Rahav O, Dubinsky Z, Achituv Y, Falkowski PG (1989) Ammonium metabolism in the zooxanthellate coral, Stylophora pistillata. Proc R Soc Lond Ser B 236:325-337

Roberts JM, Davies PS, Fixter LM (1999a) Symbiotic anemones can grow when starved: nitrogen budget for Anemonia viridis in ammonium-supplemented seawater. Mar Biol 133:29-35

Roberts JM, Davies PS, Fixter LM, Preston T (1999b) Primary site and initial products of ammonium assimilation in the symbiotic sea anemone Anemonia viridis. Mar Biol 135: 223-236

Sebens KP, Vandersall KS, Savina LA, Graham KR (1996) Zooplankton capture by two scleractinian corals, Madracis mirabilis and Montastrea cavernosa, in a field enclosure. Mar Biol 127:303-317

Sebens KP, Grace SP, Helmuth B, Maney EJ Jr, Miles JS (1998) Water flow and prey capture by three scleractinian corals, Madracis mirabilis, Montastrea cavernosa and Porites porites, in a field enclosure. Mar Biol 131: 347-360

Sokal RR, Rohlf FJ (1995) Biometry: the principles and practice of statistics in biological research, 3rd edn. WH Freeman, New York

Sorokin Y (1973) On the feeding of some scleractinian corals with bacteria and dissolved organic matter. Limnol Oceanogr 18:380-385

Steen RG (1986) Evidence for heterotrophy by zooxanthellae in symbiosis with Aiptasia pulchella. Biol Bull 170: $267-278$

Stimson J, Kinzie RA III (1991) The temporal pattern and rate of release of zooxanthellae from the reef coral Pocillopora damicornis (Linnaeus) under nitrogen-enrichment and control conditions. J Exp Mar Biol Ecol 153:63-74

Summons RE, Osmond CB (1981) Nitrogen assimilation in the symbiotic marine alga, Gymnodinium microadriaticum: Direct analysis of ${ }^{15} \mathrm{~N}$ incorporation by gas chromatographic-mass spectrometric methods. Phytochemistry 20: 575-578

Editorial responsibility: Jennifer Purcell (Contributing Editor), Anacortes, Washington, USA
Sutton DC, Hoegh-Guldberg O (1990) Host-zooxanthella interactions in four temperate marine invertebrate symbioses: Assessment of effect of host extracts on symbionts. Biol Bull 178:175-186

Swanson R, Hoegh-Guldberg O (1998) Amino acid synthesis in the symbiotic sea anemone Aiptasia pulchella. Mar Biol 131:83-93

Szmant AM, Ferrer LM, Fitzgerald LM (1990) Nitrogen excretion and atomic oxygen to nitrogen ratios in reef corals: Evidence for conservation of nitrogen. Mar Biol 104: 119-128

Szmant-Froelich A (1981) Coral nutrition: Comparison of the fate of ${ }^{14} \mathrm{C}$ from ingested labeled brine shrimp and from the uptake of $\mathrm{NaH}^{14} \mathrm{CO}_{3}$ by its zooxanthellae. J Exp Mar Biol Ecol 55:133-144

Szmant-Froelich A, Pilson MEQ (1977) Nitrogen excretion by colonies of the temperate coral Astrangia danae with and without zooxanthellae. Proc 3rd Int Coral Reef Symp 2: $417-423$

Szmant-Froelich A, Pilson MEQ (1984) Effects of feeding frequency and symbiosis with zooxanthellae on nitrogen metabolism and respiration of the coral Astrangia danae. Mar Biol 81:153-162

Thorington G, Margulis L (1981) Hydra viridis: Transfer of metabolites between Hydra and symbiotic algae. Biol Bull 160:175-188

Wang JT, Douglas AE (1998) Nitrogen recycling or nitrogen conservation in an alga-invertebrate symbiosis? J Exp Biol 201:2445-2453

Wang JT, Douglas AE (1999) Essential amino acid synthesis and nitrogen recycling in an alga-invertebrate symbiosis. Mar Biol 135:219-222

Wilkerson F, Kremer P (1992) DIN, DON and $\mathrm{PO}_{4}$ flux by a medusa with algal symbionts. Mar Ecol Prog Ser 90:237-250

Yonge CM, Nicholls AG (1931) Studies on the physiology of corals. IV. The structure, distribution and physiology of the zooxanthellae. Sci Rep Great Barrier Reef Exped 1: 135-176

Zamer WE (1986) Physiological energetics of the intertidal sea anemone Anthopleura elegantissima: I. Prey capture, absorption efficiency and growth. Mar Biol 92:299-314

Submitted: August 20, 2002; Accepted: July 28, 2003

Proofs received from author(s): October 16, 2003 